\title{
The effect of knowledge management process on the employee commitment: Evidence from digital
} marketing industry

\author{
Bui Thanh Khoa ${ }^{a^{*}}$ and Le Thi Kim Hoa ${ }^{b}$
}

${ }^{a}$ FPT University, Vietnam

${ }^{b}$ Industrial University of Ho Chi Minh City, Vietnam

CH R O N I C L E

A B S T R A C T

Article history:

Received: September 18, 2020

Received in revised format:

November 182020

Accepted: December 24, 2020

Available online:

December 24, 2020

Keywords:

Knowledge Management

Knowledge Acquisition

Knowledge Conversion

Knowledge Application

Knowledge Protection

Employee commitment

\begin{abstract}
Knowledge management is a process of systematic and transparent creation, development and application of knowledge to maximize knowledge-related performance and business value from knowledge and available wisdom assets. Knowledge management is vitally important with business and one of the competitive advantages. The aim of the study is to find out the relationship between the knowledge management process and employees' commitment in the digital marketing companies. Through the mix-method research, the research result pointed out that four dimensions of knowledge management process; i.e., Knowledge Acquisition, Knowledge Conversion, Knowledge Application, and Knowledge Protection, positively impact on the employee's commitment. Some managerial implications for the digital marketing businesses were proposed to improve the employee commitment based the knowledge management process.
\end{abstract}

\section{Introduction}

Digital Marketing takes advantage of the combination of Internet and technology devices (computers, mobile phones) and other platforms to promote marketing activities, reach users, exchange information and promote products (Khoa, 2020a). Products and services, thereby helping to increase brand awareness, build trust and maximize revenue. The work of a Digital Marketer is very diverse, ranging from search engine optimization (related to Google, Bing, Yahoo, etc.), pushing a website to the top of the search page, designing website interface, writing content (Chaffey \& Ellis-Chadwick, 2019). A blog to conduct competitor analysis, deploys email marketing channel, produce YouTube videos, TikTok. Digital Marketing is a field that constantly changes over time, has a real battle, requires the ability to update expertise, even when working constantly. Therefore, marketers need to have a firm grasp of the background before going into each area and actively grasping new trends and features. Therefore, to share knowledge to improve work efficiency (Razzaq et al., 2019). Knowledge management enriches and updates useful knowledge sources to use in the process of doing work (Indradewa et al., 2016; Svetlik et al., 2007). This activity has the effect of reducing errors, reducing repetitive tasks, reducing time and money costs; therefore, increase work performance (Aymen et al., 2019; Razzaq et al., 2019). The emergence of the knowledge economy from the end of the 20th century poses new challenges for businesses and administrators. Companies are under pressure to constantly innovate in products, services from upgrading production and business processes in order to survive and thrive in the market (Khoa, 2020b). Managers have to think about new management methods because command management and the tight control process were not suitable in a dynamic creative environment. When knowledge becomes more important than capital, labor in the composition of economic value, people think of a new central object of governance, which is knowledge management process. Knowledge management process (hereafter Knowledge Management), is seen as an important weapon to sustain

* Corresponding author.

E-mail address: khoabt3@fe.edu.vn khoadhen@gmail.com (B. T. Khoa) 
their competitive advantage and improve the business performance (Todose, 2008). It solves problems related to adaptation ith changes in the business environment and increases the survival of the organization based on transforming human capital into intellectual capital to create business value.

The understanding of knowledge management is also very different between the authors (Hlupic et al., 2002). Researching the relationship between Knowledge management - satisfaction - employee commitment results is an important and necessary issue to find out the impact of Knowledge management on human resources management results (Svetlik et al., 2007). From there, offering solutions to improve and improve employee satisfaction and job completion results in order to improve the organization's operational efficiency (Aymen et al., 2019). There are many studies on the impact of organizational commitment on the knowledge management (Gopinath, 2019; Marques et al., 2019), or the mediation role of organizational commitment in a relationship between many independent constructs and the Knowledge management (Cugueró-Escofet et al., 2019; Garrido-Moreno et al., 2014; Razzaq et al., 2019). There have been limited in the studies on the impact of knowledge management on employee commitment, especially, Knowledge management is four dimensions, including Knowledge Acquisition, Knowledge Conversion, Knowledge Application, and Knowledge Protection. Therefore, this study was conducted to measure the impact of Knowledge management process on employees' commitment in the digital marketing industry.

Excluding the introduction, the rest content of the study is arranged as follows: Part 2 presented the theories related the knowledge management process, the employee's commitment, and the relationship between all research constructs; Part 3 summarized the research method; Part 4 described the research results; Part 5 discussed the research results; and finally, part 6 showed the conclusions and managerial implications.

\section{Literature review}

\subsection{Knowledge management}

Knowledge management is the process of creating, disseminating, transferring, using and protecting existing and new knowledge (Gopinath, 2019). Knowledge management is the process of continuously managing all knowledge and skills to predict current, and future development needs to identify, explore existing knowledge as well as develop the opportunity to acquire new knowledge (Garrido-Moreno et al., 2014). In a business, the knowledge management is a continuous process from acquiring, storing, distributing and disseminating knowledge into organizational operation (Razzaq et al., 2019).

The effectiveness of knowledge management through the process with four steps: acquisition, creation, storage, and application (Aujirapongpan et al., 2010); or acquisition, conversion, application, and protection (Gold et al., 2001; Lytras \& Sicilia, 2005). Concepts, according to these approach that knowledge management process is a continuous process in acquiring/creating, transferring/converting, using/applying, and storing/protecting knowledge. Inside:

- Knowledge Acquisition is the process that the employees can access and absorb directly, or indirectly with knowledge sources (He et al., 2013). The employees acquire the knowledge from internal sources as documents, instructions on procedures, processes, transferring from colleagues; and external sources, i.e., competitor information, customer data, market data. The more information technology develops, leadership style adapts, and organizational culture about information sharing is established; the easier Knowledge Acquisition is (Aujirapongpan et al., 2010; Gold et al., 2001).

- Knowledge Conversion is the process that the knowledge is converted to make it useful. The knowledge is coded to meet the users' need in their job. The Knowledge Conversion process includes knowledge integration, coordination, restructure, and distribution of knowledge (Gold et al., 2001).

- Knowledge Application describes the process that employees and organizations use knowledge in their business (Gold et al., 2001). The result of Knowledge Application is to develop and inovate the product or service to improve the business performance and reduce production costs (Razzaq et al., 2019).

- Knowledge Protection is the step that the businesses stores, refine to make it useful and valuable to the organization/ The knowledge has a role as organizational intelligence, i.e., protect, maintain and preserve knowledge (Aujirapongpan et al., 2010; Gopinath, 2019)

\subsection{Employee Commitment}

Employee Commitment is defined as an employee's enduring desire to maintain a quality relationship with the company (Moorman et al., 1992; Plewa \& Quester, 2006). Commitment arises when both sides (company and employee) recognize the importance of a relationship and then work together to ensure the relationship is sustainable (Morgan \& Hunt, 1994). Commitment includes a sense of commitment to work, loyalty and belief in the organization's values (Meyer et al., 2012). According to Allen and Meyer (1990), employee's commitment to the organization is measured based on their belief in the organization, their acceptance of the organization's goals and values, and their willingness to work hard for organization, and want to become a member of the organization (Nijhof et al., 1998). Commitment to the organization is based on three components: Affective, continuance, and normative commitment (Allen \& Meyer, 1996). In which, affective commitment is a decisive factor to the dedication and loyalty of employees to the business. (Rhoades et al., 2001). Employees with affective commitment are considered familiar and will increase their participation in the activities of the organization, and they are also willing to pursue the goals of the organization and desire to work for the long term at business (Meyer \& Allen, 1991). 
When businesses build a continuous flow of communication in the organization, and there is social interaction among employees, knowledge sharing will be formed. The greater the formation of sharing rules, the greater the employee's commitment to regulation (Song et al., 2006). Employee's high commitment to the organization when the company is successful in creating and sharing knowledge (Alvesson, 2000). Employees' commitment will not be created unless there is a clear rule governing knowledge of workers (Cabrera \& Cabrera, 2005). Therefore, four the dimensions of knowledge management process would have a positive impact on employee commitment as the Figure 1. The hypotheses were proposed:

Hypothesis 1: Knowledge Acquisition has a positive impact on employee commitment.

Hypothesis 2: Knowledge Conversion has a positive impact on employee commitment.

Hypothesis 3: Knowledge Application has a positive impact on employee commitment.

Hypothesis 4: Knowledge Protection has a positive impact on employee commitment.

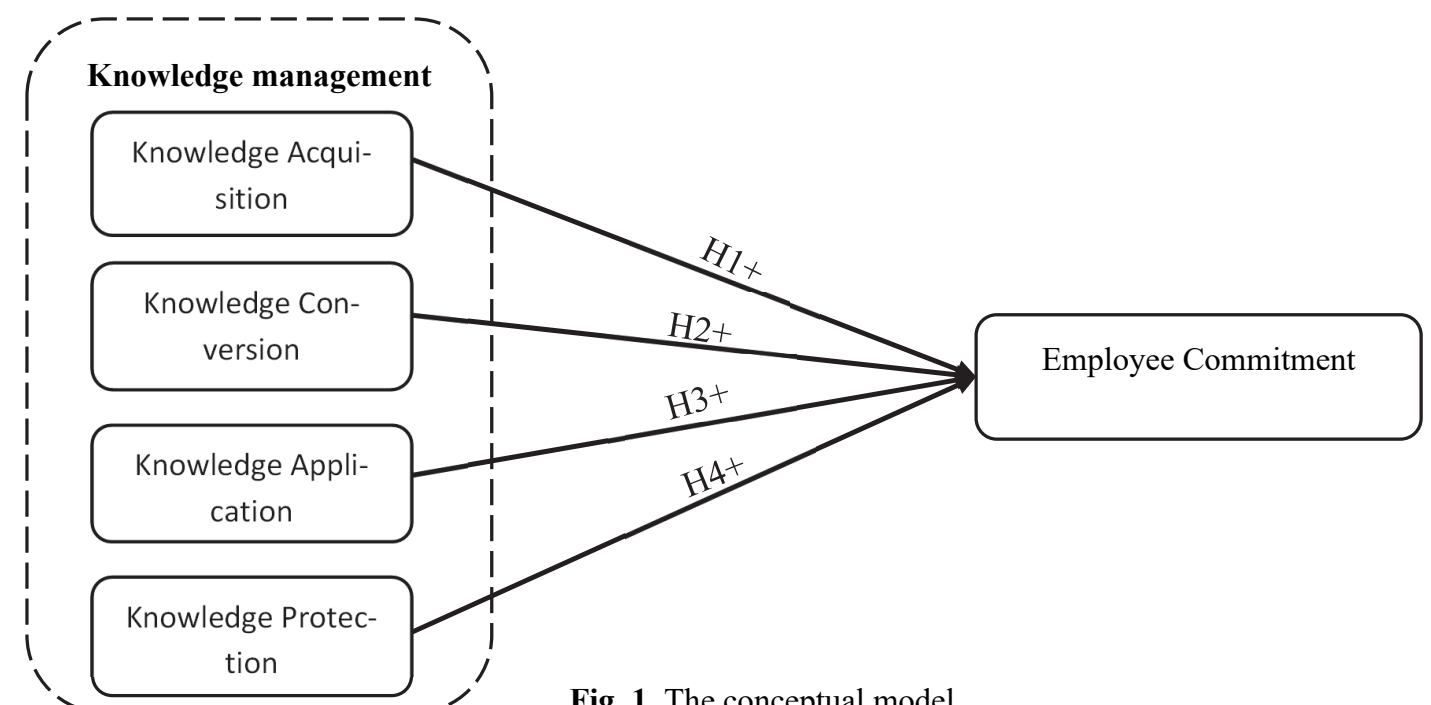

\section{Research method}

This research method included qualitative and quantitative research methods. The qualitative research method was used to confirm and adjust the measurement scales, which were adopted from the previous studies (Khoa \& Nguyen, 2020). The data in qualitative research was collected from group discussion with nine experts, who are the middle and top management, as well as the experts in the human resources in the digital marketing company. The discussion lasted 3 hours and took place in the meeting room of Innoteq Company, a digital marketing (innoteq.vn). The authors were the chair to control the discussion and took note of the main ideas. The discussion content also was recorded. The focus groups discussion result pointed out that the research model and all the scales were suitable for the survey. A questionnaire using a five-point Likert scale was used to collect data for each construct of the study. The instrument development was based on previous studies. Table 1 summarizes the items used in each scale.

\section{Table 1}

The measurement scale

\begin{tabular}{|c|c|c|}
\hline Construct & Items & Source \\
\hline $\begin{array}{l}\text { Knowledge Acqui- } \\
\text { sition } \\
\text { (ACQ) }\end{array}$ & $\begin{array}{l}\text { My company has processes for... } \\
\text { ACQ1 - ... generating new knowledge from existing knowledge } \\
\text { ACQ2 - . . using feedback from projects to improve subsequent projects } \\
\text { ACQ3 - ...distributing knowledge throughout my company } \\
\text { ACQ4 - . . exchanging knowledge with our business partner } \\
\text { ACQ5 - . . acquiring knowledge about new products/services within the digital marketing industry } \\
\text { ACQ6 - . . acquiring knowledge about competitor within our digital marketing }\end{array}$ & Gold et al. (2001) \\
\hline $\begin{array}{l}\text { Knowledge Conver- } \\
\text { sion } \\
(\mathrm{CON})\end{array}$ & $\begin{array}{l}\text { My company has processes for... } \\
\text { CON1 - ...filtering knowledge } \\
\text { CON } 2 \text { - ...transferring organizational knowledge to individuals. } \\
\text { CON } 3-\ldots \text { absorbing knowledge from individuals into my company } \\
\text { CON } 4-\ldots \text { integrating different sources and types of knowledge. }\end{array}$ & Gold et al. (2001) \\
\hline $\begin{array}{l}\text { Knowledge Appli- } \\
\text { cation } \\
\text { (APP) }\end{array}$ & $\begin{array}{l}\text { My company has... } \\
\text { APP1 - applied knowledge learned from mistakes. } \\
\text { APP2 - used knowledge to solve new problems } \\
\text { APP3 - used knowledge to improve efficiency } \\
\text { APP4 - matched sources of knowledge to problems and challenges } \\
\text { APP5 - quickly applied knowledge to critical competitive needs }\end{array}$ & Gold et al. (2001) \\
\hline
\end{tabular}




\begin{tabular}{|c|c|c|}
\hline Construct & Items & Source \\
\hline $\begin{array}{l}\text { Knowledge Protec- } \\
\text { tion } \\
(\mathrm{PRO})\end{array}$ & $\begin{array}{l}\text { My company has. } \\
\text { PRO1 - ... processes to protect knowledge from inappropriate use inside my company } \\
\text { PRO2 - ...has processes to protect knowledge from theft within my company } \\
\text { PRO3 - ...valued and protected knowledge embedded in individuals } \\
\text { PRO4 - Knowledge that is restricted is identified } \\
\text { PRO5 - Clearly communicates the importance of protecting knowledge. }\end{array}$ & Gold et al. (2001) \\
\hline $\begin{array}{l}\text { Employee Commit- } \\
\text { ment } \\
(\mathrm{COM})\end{array}$ & $\begin{array}{l}\text { COM1 - I consider knowledge management to be a } \\
\text { top priority. } \\
\text { COM2 - I motivate and encourage my colleague to share the knowledge } \\
\text { COM3 - My performance is measured and rewarded based on my ability to share the knowledge } \\
\text { COM4 - Training programs are designed to help me develop the skills needed to manage the knowledge } \\
\text { sharing process effectively. } \\
\text { COM5 - I committed to using knowledge sharing system to achieve high levels of job performance. }\end{array}$ & $\begin{array}{l}\text { Garrido-Moreno } \\
\text { et al. }(2014)\end{array}$ \\
\hline
\end{tabular}

The respondents in the study were the employees in the digital marketing company in Vietnam, aged from 25 years old. The sampling method was purposive sampling in non-probability sampling. Out of 700 self-administered questionnaires distributed by mail, a total of 611 completed responses were collected. The value has already fulfilled the minimum response rate of approximately $87.3 \%$. The respondent's description was shown in Fig. 2. All data were already well screened and used the SmartPLS software for PLS-SEM analysis.

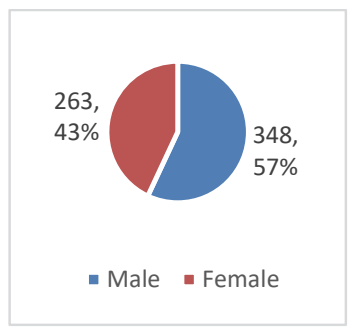

Gender

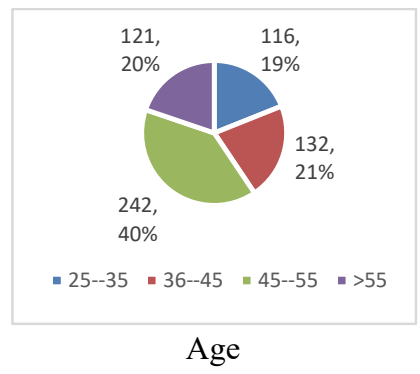

Fig. 2. The respondents' description

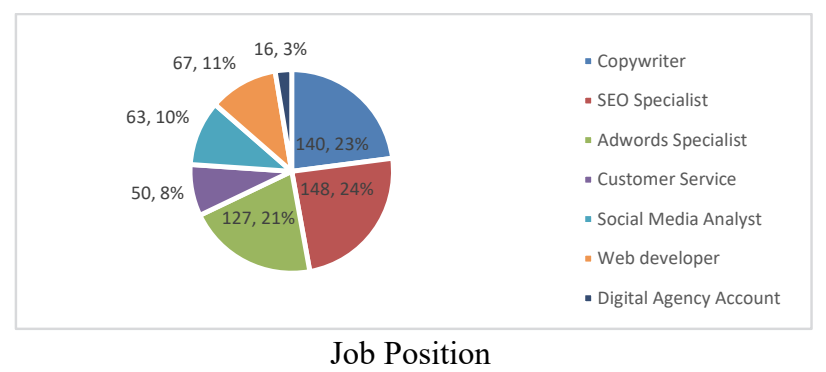

Job Position

This study used the PLS-SEM (Partial Least Squares Structural Equation Modeling) to process the data and test the research hypotheses. Using proxies as input, PLS-SEM applies Ordinary Least Squares to minimize error terms (such as residual variance) of endogenous constructs. PLS-SEM estimates the coefficients (i.e., the path model relationship) such that to maximize the $\mathrm{R}^{2}$ values of the endogenous (target) construct, which achieves the predicted target of PLS-SEM. Thus, PLS-SEM is the preferred method when the purpose of the research is to develop the theory and explain the variance (prediction of structures).

\section{Research result}

\subsection{The measurement scale reliability}

Reliability test is to confirm whether an instrument consistently measures the construct. Cronbach's Alpha coefficient (CA) is a statistical test of the degree of rigour of questionable items on the scale-correlated. The reliable measurement scale has the 0.7 or greater of CA. The inconsistent items will be removed if the Corrected Item - Total Correlation is less than 0.3 . The $\mathrm{CA}$ of 05 constructs in the research was shown in Table 2 . All CA of measurement scales were higher than $0.7\left(\mathrm{CA}_{\mathrm{min}}=\right.$ 0.852), the Corrected Item - Total Correlation of all items in the research were greater than 0.3 (minimum Corrected Item Total Correlation was 0.587 ). Therefore, all measurement scale got reliability.

Table 2

The reliability of measurement scale

\begin{tabular}{|c|c|c|}
\hline Construct & Cronbach's Alpha & Corrected Item-Total Correlation \\
\hline $\mathrm{ACQ}$ & 0.874 & {$[0.63-0.713]$} \\
\hline APP & 0.933 & {$[0.778-0.852]$} \\
\hline $\mathrm{COM}$ & 0.852 & {$[0.587-0.731]$} \\
\hline $\mathrm{CON}$ & 0.881 & {$[0.649-0.848]$} \\
\hline PRO & 0.91 & {$[0.729-0.861]$} \\
\hline
\end{tabular}

\subsection{The measurement scale validity}

This research assessed the scale validity through convergent validity and discriminant validity (Hair et al., 2016). The result in Table 3 showed that the highest HTMT was 0.739 (between PRO and COM), which was less than 0.85. Consequently, the discriminant validity of all the scales was archived. The convergent validity was evaluated via three criteria, including (1) the Composite Reliability (CA), which is equal or more than 0.7 ; (2) Average Variance Extracted (AVE), which is equal or more than 0.5 ; (3) outer loading, which is more than 0.708 . All criteria above were met the threshold in Table 5; hence, all measurement scale had the convergent validity. Heterotrait-Monotrait Ratio (HTMT) between two constructs is used to assess the discriminant validity. The threshold of HTMT is lower than 0.85 , will show the discriminant. 
Table 3

The result of discriminant analysis

\begin{tabular}{cccc}
\hline & ACQ & APP & COM \\
\hline APP & 0.459 & & \\
COM & 0.635 & 0.772 & 0.626 \\
CON & 0.601 & 0.451 & 0.739 \\
PRO & 0.473 & 0.498 & 0.45 \\
\hline
\end{tabular}

\section{Table 4}

The result of convergent validity.

\begin{tabular}{|c|c|c|c|c|c|c|c|}
\hline \multirow{2}{*}{ Items } & \multicolumn{5}{|c|}{ Outer loading } & \multirow{2}{*}{$\mathrm{CA}$} & \multirow{2}{*}{ AVE } \\
\hline & ACQ & APP & $\mathrm{COM}$ & $\mathrm{CON}$ & PRO & & \\
\hline ACQ1 & 0.818 & & & & & \multirow{6}{*}{0.905} & \multirow{6}{*}{0.613} \\
\hline ACQ2 & 0.79 & & & & & & \\
\hline ACQ3 & 0.789 & & & & & & \\
\hline ACQ4 & 0.787 & & & & & & \\
\hline ACQ5 & 0.751 & & & & & & \\
\hline ACQ6 & 0.761 & & & & & & \\
\hline APP1 & & 0.911 & & & & \multirow{5}{*}{0.949} & \multirow{5}{*}{0.788} \\
\hline APP2 & & 0.893 & & & & & \\
\hline APP3 & & 0.895 & & & & & \\
\hline APP4 & & 0.884 & & & & & \\
\hline APP5 & & 0.854 & & & & & \\
\hline COM1 & & & 0.82 & & & \multirow{5}{*}{0.894} & \multirow{5}{*}{0.629} \\
\hline COM2 & & & 0.8 & & & & \\
\hline COM3 & & & 0.836 & & & & \\
\hline COM4 & & & 0.736 & & & & \\
\hline COM5 & & & 0.772 & & & & \\
\hline CON1 & & & & 0.833 & & \multirow{4}{*}{0.919} & \multirow{4}{*}{0.739} \\
\hline CON2 & & & & 0.797 & & & \\
\hline CON3 & & & & 0.925 & & & \\
\hline CON4 & & & & 0.879 & & & \\
\hline PRO1 & & & & & 0.823 & \multirow{5}{*}{0.933} & \multirow{5}{*}{0.737} \\
\hline PRO2 & & & & & 0.84 & & \\
\hline PRO3 & & & & & 0.866 & & \\
\hline PRO4 & & & & & 0.847 & & \\
\hline PRO5 & & & & & 0.913 & & \\
\hline
\end{tabular}

\subsection{The PLS-SEM}

The PLS-SEM, which has the bootstrap procedure with 5000 random subsamples, was assessed with five criteria (Khoa et al., 2020).

- Collinearity is assessed through VIF value is less than 2 .

- Coefficient of Determination $\left(\mathrm{R}^{2}\right)$ values $0.75,0.50$, or 0.25 ; respectively, the substantial, moderate, or weak explanation of the change of dependent construct under the impact of the independent construct.

- Effect Size $\left(\mathrm{f}^{2}\right)$ value 0.02, 0.15, and 0.35; respectively, represent small, medium, and large effects the exogenous latent variable.

- $\quad$ Predictive Relevance $\left(\mathrm{Q}^{2}\right)$ must be larger than 0 .

- Lastly, Path Coefficient is assessed through the p-value, which is less than 0.05 in $95 \%$ of confidence level.

The table 6 pointed out that all the VIF value is smaller than 2; hence, there was no collinearity between the constructs in the research model. The COM was explained in $67.4 \%$ by the change of independent variables. The APP and PRO have the medium effect size on the COM; respectively, 0.349 and 0.257 ; ACQ and CON have the small effect size on COM with $\mathrm{f}^{2}$ value, respectively, were $0.048,0.049$. The result of the $\mathrm{Q}^{2}$ value in Table 6 was more than $0\left(\mathrm{Q}^{2} \mathrm{CON}=0.415\right)$.

Table 5

The result of VIF, $\mathrm{R}^{2}, \mathrm{f}^{2}$, and $\mathrm{Q}^{2}$

\begin{tabular}{|c|c|c|c|c|}
\hline 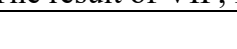 & VIF & $\mathrm{R}^{2}$ & $\mathrm{f}^{2}$ & $\mathrm{O}^{2}$ \\
\hline Construct & $\mathrm{COM}$ & $\mathrm{R}^{2}$ & $\mathrm{COM}$ & \\
\hline ACQ & 1.547 & \multirow{5}{*}{0.674} & 0.048 & \multirow{5}{*}{0.415} \\
\hline APP & 1.417 & & 0.349 & \\
\hline $\mathrm{COM}$ & & & & \\
\hline $\mathrm{CON}$ & 1.513 & & 0.049 & \\
\hline PRO & 1.424 & & 0.257 & \\
\hline
\end{tabular}

In Table 6, four the path coefficients in this study were accepted from 0.156 to 0.402 , and the p-value of the valid path coefficients were 0.00, which is less than 0.001. Hence, the PLS-SEM could describe in the regression model as:

$$
C O M=0.156 \times A C Q+0.402 \times A P P+0.156 \times C O N+0.345 \times P R O
$$


Table 6

The PLS-SEM result

\begin{tabular}{|c|c|c|c|c|}
\hline Relationships & Original Sample $(\mathrm{O})$ & Standard Deviation (STDEV) & T Statistics (|O/STDEV $\mid)$ & P Values \\
\hline $\mathrm{ACQ} \rightarrow \mathrm{COM}$ & 0.156 & 0.031 & 5.022 & 0.00 \\
\hline $\mathrm{APP} \rightarrow \mathrm{COM}$ & 0.402 & 0.031 & 12.752 & 0.00 \\
\hline $\mathrm{CON} \rightarrow \mathrm{COM}$ & 0.156 & 0.030 & 5.143 & 0.00 \\
\hline $\mathrm{PRO} \rightarrow \mathrm{COM}$ & 0.345 & 0.032 & 10.777 & 0.00 \\
\hline
\end{tabular}

\section{Discussion}

People are living in an age where the world economy is transforming from an economy based mainly on the limited resources of nature to an economy of information and intelligence. Natural resources are excluded from the competition program; knowledge and skills are the only resources that create a sustainable competitive advantage (Nguyen \& Khoa, 2020). In terms of hierarchy, knowledge is at the highest position in the chain of data - information - knowledge concepts (Liew, 2007). Data is a set of discrete, objective facts or facts presented without judgment or with no context. Data can exist in the form of text, images, or sound. When data is processed, i.e., through classification, analysis, synthesis, put into a context and becomes meaningful to the recipient, it becomes information. It can be said that information is meaningful data after it has been processed. Information becomes knowledge when it is perceived and valued through the critical reception of thought. It can be said that knowledge is useful information perceived by human intellect (Cooper, 2017).

Firstly, Knowledge Acquisition had a significant positive impact on employee commitment (beta $=0.156$, sig. $=0.00$ ); hence, the hypothesis H1 was accepted. Knowledge Acquisition is the input of the Knowledge Management process; hence, it is vitally important to develop the process. The quality and quantity of input information will create good or bad knowledge (Koskinen et al., 2003). The good process of knowledge gathering will create the satisfaction and connection of employees with the business because they feel fair values in the future when working at the company (Roy \& Thérin, 2008). Business enterprises in the digital marketing field need to have active solutions, such as building an online database system to store instructions and feedback after each project. Also, enterprises need to build consumer intelligence systems or marketing/management information system (MIS) to exchange and acquire the knowledge from the markets, competitors, partners.

Knowledge Conversion is the next step after the businesses acquire knowledge. In this research, Knowledge Conversion had a positive effect on Employee Commitment (Beta $=0.156$, sig. $=0.00)$; hence, the hypothesis $\mathrm{H} 2$ was accepted.. The degree of impact of Conversion Knowledge and Acquisition Knowledge on Employee Commitment is the same. With the development of science and technology, it should be assumed that acquiring knowledge will be easy, and more knowledge will be gathered (Curado \& Vieira, 2019); therefore, digital marketing businesses need to know how to refine their knowledge to remove useless knowledge and keep the useful ones (Konnot, 1994). Besides, transforming business knowledge into personal knowledge is also important. A digital marketing agency needs a data processing system that can even group data collected from the marketplace. Besides, short training sessions are also a method to cover knowledge from the organization to the employees of the digital marketing industry.

Knowledge Application in digital marketing enterprises positively impacts employee commitment $($ Beta $=0.402$, sig. $=0.00)$; hence, the hypothesis H3 was accepted. The application of knowledge has the strongest impact on the four factors on employee engagement in digital marketing firms. In fact, for employees, the application of knowledge at work is the most concrete step that shows the value of knowledge management in the enterprise (Razzaq et al., 2019). The application of knowledge will create efficiency and productivity of employees' work; thereby, they will feel the benefits of knowledge management in the working process and become more connected to the current work (Curado \& Vieira, 2019). Enterprises need to employ their knowledge to solve problems at work, or even case by case for similar jobs to improve job efficiency. Enterprises simultaneously build a database of common activities or problems so that the application of knowledge can take place faster and more efficiently, thereby enhancing the competitiveness of businesses.

Last but not least, Knowledge Protection is one of the most important steps in the Knowledge Management process. Based the research result, the Knowledge Protection positively effect on the Employee Commitment $($ Beta $=0.345$, sig. $=0.00)$; therefore, the hypothesis H4 was accepted. Because of the important nature of knowledge, it is important to protect against knowledge theft. In many cases, knowledge is not only stolen by external theft, but also by an employee of the business (Cumin et al., 2019; Smith et al., 2011). Identification when accessing the management system needs to be taken seriously. Besides, propaganda through email, website and local message boards, and the enterprise must provide specific penalties if there are threats, data theft and enterprise knowledge.

\section{Conclusion}

This study has examined the relationship between a knowledge management process and employee commitment in the digital marketing company. Qualitative research ensured the suitability of the items, as well as the relationship between the constructs. Additionally, the study also used survey methods in quantitative research. Through analyzing 611 responses, research has shown that Knowledge Application had the strongest impact on Employee Commitment; as well as Knowledge Acquisition and Knowledge Conversion had the lowest effect on the Employee Commitment. This study has not only theoretical but also practical contributions. Theoretically, this study based on the four dimensions of Knowledge Management Process of (Gold et al., 2001); i.e., Knowledge Acquisition, Knowledge Conversion, Knowledge Application, and Knowledge Protection, to assess the relationship between the Knowledge Management process and Employee Commitment. The result pointed 
out that there is a positive impact of Knowledge Management on Employee Commitment. Hence, the commitment of the employee may be the consequence of the organization and using data in the business. Practically, the research proposed many managerial implications for the business to improve employee commitment with the company and their job. The main motivating solutions focused on the Knowledge Application and Knowledge Protection, two final steps in the Knowledge Management process.

The limitations of a study are inevitable; however, there are opportunities for further studies. Despite certain efforts, this study still had some limitations. First, this research was only focused on the digital marketing industry, closely linked with knowledge management's dynamic. Another was a discrete assessment of dimensions of knowledge management that affect employee commitment. Further studies may expand disciplines closely related to knowledge management to demonstrate the stability of the model. Another step forward in research is to compare and evaluate two-way relationships between knowledge management and employee commitment. Finally, further studies can assess knowledge management as a formative concept in measuring the relationship between knowledge management and other constructs.

\section{References}

Allen, N. J., \& Meyer, J. P. (1996). Affective, continuance, and normative commitment to the organization: An examination of construct validity. Journal of Vocational Behavior, 49(3), 252-276.

Alvesson, M. (2000). Social indentity and the problem of loyalty in knowledge-intensive companies. Journal of management studies, 37(8), 1101-1124.

Aujirapongpan, S., Vadhanasindhu, P., Chandrachai, A., \& Cooparat, P. (2010). Indicators of knowledge management capability for KM effectiveness. Vine, 40(2), 183-203. doi: https://10.1108/03055721011050677

Aymen, R. A., Alhamzah, A., \& Bilal, E. (2019). A multi-level study of influence financial knowledge management small and medium enterprises. Polish Journal of Management Studies, 19.

Cabrera, E. F., \& Cabrera, A. (2005). Fostering knowledge sharing through people management practices. The International Journal of Human Resource Management, 16(5), 720-735.

Chaffey, D., \& Ellis-Chadwick, F. (2019). Digital marketing: Pearson UK.

Cooper, P. (2017). Data, information, knowledge and wisdom. Anaesthesia \& Intensive Care Medicine, 18(1), 55-56.

Cugueró-Escofet, N., Ficapal-Cusí, P., \& Torrent-Sellens, J. (2019). Sustainable human resource management: How to create a knowledge sharing behavior through organizational justice, organizational support, satisfaction and commitment. Sustainability, 11(19), 5419.

Cumin, D., Callagher, L., Husted, K., \& Cheung, G. W. H. (2019). The moderating effect of Top Management Support and Knowledge Protection Mechanisms on the relationship between Commitment and Knowledge Sharing Behaviour in Collaborative Innovation. Paper presented at the ISPIM Conference Proceedings.

Curado, C., \& Vieira, S. (2019). Trust, knowledge sharing and organizational commitment in SMEs. Personnel Review, 48(6), 1449-1468. doi: https://10.1108/pr-03-2018-0094

Garrido-Moreno, A., Lockett, N., \& García-Morales, V. (2014). Paving the way for CRM success: The mediating role of knowledge management and organizational commitment. Information \& Management, 51(8), 1031-1042.

Gold, A. H., Malhotra, A., \& Segars, A. H. (2001). Knowledge management: An organizational capabilities perspective. Journal of Management Information Systems, 18(1), 185-214.

Gopinath, R. (2019). Impact of Organisational Commitment on Knowledge Management Practices. International Journal of Research and Analytical Reviews, 6(2), 701-703.

Hair, J. F., Hult, G. T. M., Ringle, C., \& Sarstedt, M. (2016). A primer on partial least squares structural equation modeling (PLS-SEM). London: Sage publications. doi: https://10.15358/9783800653614

He, Q., Ghobadian, A., \& Gallear, D. (2013). Knowledge acquisition in supply chain partnerships: The role of power. International Journal of Production Economics, 141(2), 605-618.

Hlupic, V., Pouloudi, A., \& Rzevski, G. (2002). Towards an integrated approach to knowledge management: 'hard','soft'and 'abstract'issues. Knowledge and Process Management, 9(2), 90-102.

Indradewa, R., Tjakraatmadja, J. H., \& Dhewanto, W. (2016). Alliance strategy in R\&D contractual projects for the energy sector: perspective of the knowledge and resource-based views. International Journal of Technology Transfer and Commercialisation, 14(1), 1-19.

Khoa, B. T. (2020a). The Impact of the Personal Data Disclosure's trade-off on the Trust and Attitude Loyalty in Mobile Banking Services. Journal of Promotion Management, ahead-of-print(ahead-of-print). doi: https://10.1080/10496491.2020.1838028

Khoa, B. T. (2020b). The role of Mobile Skillfulness and User Innovation toward Electronic Wallet Acceptance in the Digital Transformation Era. Paper presented at the 2020 International Conference on Information Technology Systems and Innovation (ICITSI), Bandung - Padang, Indonesia. doi: https://10.1109/ICITSI50517.2020.9264967

Khoa, B. T., \& Nguyen, H. M. (2020). Electronic Loyalty In Social Commerce: Scale Development and Validation. Gadjah Mada International Journal of Business, 22(3), 275-299. doi: https://10.22146/gamaijb.50683

Khoa, B. T., Nguyen, H. M., Tran, N. V. H., \& Nguyen, B. H. (2020). Lecturers' adoption to use the online Learning Management System (LMS): Empirical evidence from TAM2 model for Vietnam. Journal of Science Hcmcou Economics \& Business Administration, 10(1), 3-17. doi: https://10.46223/HCMCOUJS.econ.en.10.1.216.2020 
Konnot, N. (1994). Organizational knowledge creation theory: a first comprehensive test. International Business Review, 3(4), 337-351.

Koskinen, K. U., Pihlanto, P., \& Vanharanta, H. (2003). Tacit knowledge acquisition and sharing in a project work context. International Journal of Project Management, 21(4), 281-290.

Liew, A. (2007). Understanding data, information, knowledge and their inter-relationships. Journal of Knowledge Management Practice, 8(2), 1-16.

Lytras, M. D., \& Sicilia, M. A. (2005). The Knowledge Society: a manifesto for knowledge and learning. International Journal of Knowledge and Learning, 1(1-2), 1-11.

Marques, J. M. R., La Falce, J. L., Marques, F. M. F. R., De Muylder, C. F., \& Silva, J. T. M. (2019). The relationship between organizational commitment, knowledge transfer and knowledge management maturity. Journal of Knowledge Management, 23(3), 489-507. doi: https://10.1108/jkm-03-2018-0199

Meyer, J. P., \& Allen, N. J. (1991). A three-component conceptualization of organizational commitment. Human Resource Management Review, 1(1), 61-89.

Meyer, J. P., Stanley, L. J., \& Parfyonova, N. M. (2012). Employee commitment in context: The nature and implication of commitment profiles. Journal of Vocational Behavior, 80(1), 1-16.

Moorman, C., Zaltman, G., \& Deshpande, R. (1992). Relationships between providers and users of market research: The dynamics of trust within and between organizations. Journal of Marketing Research, 29(3), 314-328.

Morgan, R. M., \& Hunt, S. D. (1994). The commitment-trust theory of relationship marketing. The Journal of Marketing, 58(3), 20-38. doi: https://https://doi.org/10.1177/002224299405800302

Nguyen, M. T., \& Khoa, B. T. (2020). Improving the Competitiveness of Exporting Enterprises: A Case of Kien Giang Province in Vietnam. The Journal of Asian Finance, Economics and Business, 7(6), 495-508. doi: https://10.13106/jafeb.2020.vol7.no6.495

Nijhof, W. J., de Jong, M. J., \& Beukhof, G. (1998). Employee commitment in changing organizations: an exploration. Journal of European Industrial Training, 22(6), 243-248. doi: https://10.1108/03090599810224701

Plewa, C., \& Quester, P. (2006). Satisfaction with university-industry relationships: the impact of commitment, trust and championship. International Journal of Technology Transfer and Commercialisation, 5(1-2), 79-101.

Razzaq, S., Shujahat, M., Hussain, S., Nawaz, F., Wang, M., Ali, M., \& Tehseen, S. (2019). Knowledge management, organizational commitment and knowledge-worker performance: The neglected role of knowledge management in the public sector. Business Process Management Journal, 25(5), 923-947. doi: https://10.1108/bpmj-03-2018-0079

Rhoades, L., Eisenberger, R., \& Armeli, S. (2001). Affective commitment to the organization: the contribution of perceived organizational support. Journal of Applied Psychology, 86(5), 825-836. doi: https://10.1037/0021-9010.86.5.825

Roy, M. J., \& Thérin, F. (2008). Knowledge acquisition and environmental commitment in SMEs. Corporate Social Responsibility and Environmental Management, 15(5), 249-259.

Smith, H. J., Dinev, T., \& Xu, H. (2011). Information privacy research: an interdisciplinary review. MIS quarterly, 35(4), 989-1016.

Song, M., van der Bij, H., \& Weggeman, M. (2006). Factors for improving the level of knowledge generation in new product development. R\&D Management, 36(2), 173-187.

Svetlik, I., Svetlik, I., \& Stavrou-Costea, E. (2007). Connecting human resources management and knowledge management. International Journal of Manpower, 28(3/4), 197-206. doi: https://10.1108/01437720710755209

Todose, D. (2008). Education management in knowledge based society. Contemporary Economics, 2(3), 109-117.

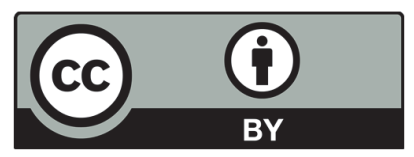

(C) 2021 by the authors; licensee Growing Science, Canada. This is an open access article distributed under the terms and conditions of the Creative Commons Attribution (CC-BY) license (http://creativecommons.org/licenses/by/4.0/). 